\title{
Monopoly Power with a Short Selling Constraint
}

\author{
By \\ Robert Baumann, \\ Bryan Engelhardt \\ and \\ David L. Fuller
}

April 2016

\section{COLLEGE OF THE HOLY CROSS, DEPARTMENT OF ECONOMICS FACULTY RESEARCH SERIES, PAPER NO. 16-03*}

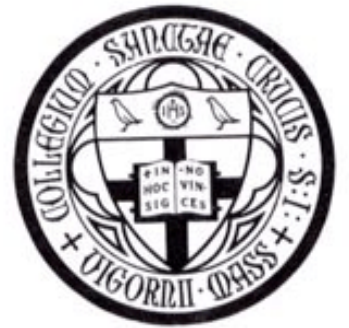
Department of Economics College of the Holy Cross Box 45A
Worcester, Massachusetts 01610
(508) 793-3362 (phone)

(508) 793-3710 (fax)

http://www.holycross.edu/academics/programs/economics-and-accounting

* All papers in the Holy Cross Working Paper Series should be considered draft versions subject to future revision. Comments and suggestions are welcome. 


\title{
Monopoly Power with a Short Selling Constraint
}

\author{
Robert Baumann* \\ College of the Holy Cross
}

\author{
Bryan Engelhardt ${ }^{\dagger}$ \\ College of the Holy Cross
}

April 15, 2016

\author{
David L. Fuller ${ }^{\ddagger}$ \\ University of Wisconsin, Oshkosh
}

\begin{abstract}
We show if a speculator can benefit from reducing a monopoly's rents through short selling, then a speculator may take a short position in a monopoly, overcome the barriers to entry, and compete with the monopoly. The competition drives down the monopoly's rents, and as a result, the short position becomes profitable and covers the cost of entry. If entry is impossible, then the speculator may coordinate and pay the firm's counter-parties to stop trading with the monopoly rather than entering. Either way, increasing a speculator's ability to short a firm's rents results in a constraint on the monopoly and forces it to act more like a price taker. The mechanism is a market based approach to antitrust.
\end{abstract}

Keywords: antitrust, monopoly, short selling

JEL Codes: L12, K21

${ }^{*}$ Department of Economics, College of the Holy Cross, One College Street, Worcester, MA 01610, rbaumann@holycross.edu.

${ }^{\dagger}$ Department of Economics, College of the Holy Cross, One College Street, Worcester, MA 01610, bengelha@holycross.edu.

${ }^{\ddagger}$ UW Oshkosh College of Business, 800 Algoma Blvd., Oshkosh, WI 54901, fullerd@uwosh.edu. 


\section{Introduction}

Arbitrage Pricing Theory suggests short selling as a critical tool to efficiently price assets. Others argue short selling is destructive and inappropriately drives down the price of an asset. The widely accepted uptick rule embodies the argument against short selling. We add to both sides by demonstrating how short selling, i.e., a position with a negative delta relative to a particular asset, can drive down the stock price of a monopoly and improve market efficiency. Specifically, short selling provides the ability for a third party, such as a speculator, to take a short position, use a portion of the funds from the position to overcome the barriers to entry, price the product more competitively, drive down the monopoly's rents (or profits) and share price, and with the remaining funds close the short position at a fraction of the original price. To put it differently, an argument can easily be made that the ability to take a negative delta position improves market efficiency, drives down the stock price of monopolies, and provides a completely new approach to antitrust. It relates to antitrust because the speculator can only drive down the stock price when the firm retains economic rents as seen in monopolies.

The argument that the speculator can drive the firm's profits to zero applies even if the barriers to entry are insurmountable. The inefficiencies resulting from monopoly behavior can still be eliminated if the speculator is able to use the funds from the short sale to coordinate a boycott of the firm. In other words, the argument still works if the speculator can pay the monopoly's consumers or monopsonist's workers to stop trading with the firm. The threat of the boycott induces the firm to price as if it were in a competitive market. The coordination can be applied to a variety of scenarios where monopolies are guaranteed such as a public utility. Unionization is a good example of where a boycott, or strike, can be organized.

To support the argument, we formally model the monopolist and counter-party in a simple oneperiod representative agent model. We show the speculator can constrain the monopolist's profits if (i) a speculator can both anonymously short a sufficiently large amount of the monopolist's stock and profit from a decline in its monopolistic rents and (ii) the speculator can pay a fixed cost and enter the market or coordinate the firm's counter-party by paying the counter-party to boycott the firm. In equilibrium, the speculator never enters or coordinates, but the threat moves the price of the firm's good closer to the competitive price. If the speculator can enter into a sufficiently large short position, then the firm will price its good at a point where profits are zero, i.e., as if it were in a 
competitive market. The model is provided in Section 2. We discuss in Section 3 the possibility of whether the "short selling constraint" binds, i.e., whether monopolies make decisions on whether a speculator might enter.

Our work applies to several very large literatures. It relates to antitrust. Specifically, we recommend monopoly behavior be eliminated by requiring monopoly firms to be publicly traded and for courts to eliminate limits on short selling of the monopoly firm's stock. It relates to the theory of the firm and asset pricing. It suggests short selling should be used to manipulate not only the price of the asset but the underlying firm's actions. Specifically, the results show how the ability to take a negative delta position on an asset, such as short selling a publicly traded company, can influence the firm's decisions without voting rights or any direct influence on the firm's actions. We find the most closely related work to be Renstrom and Yalcin [2003]. They show if workers or consumers are shareholders of the firm, can vote on its actions and short selling is not constrained, then the firm behaves like a price taker. The key difference in our model is neither the firm's counter-party (consumer or worker) nor the speculator can directly affect the actions of the firm. We find the speculator, with the ability to short sell, can simply threaten the monopolist's rents and constrain them to make a particular decision without any direct influence. Furthermore, their work is focused on corporate governance and not a situation where profits are nfecessarily maximized. As they suggest, our work has connections to Coase's Theorem as formulated in Coase [1960]. However, it is only tangentially related in the sense that the ability to trade the monopoly, or source of the market inefficiency, can reduce or eliminate the inefficiency. Furthermore, it is only loosely related because our result requires individuals to be able to sell the asset without owning it.

\section{Model}

Our objective in this section is to highlight, in a transparent way, how the threat of short selling may induce a firm to operate as if it were a price taker and thus at the efficient level. We consider two different scenarios. First, we consider a situation where the industry has a fixed cost of entry and no entrants without short selling. The second scenario assumes entry is impossible such as a government sanctioned public utility. We will take the final good's price as the numeraire good and assume the monopoly firm offers a wage $w$ in such a way to extract rents. It can easily be reversed. The threat of a short selling player, which we will refer to as a speculator, will result in the firm 
hiring more labor at a higher wage. Furthermore, we characterize the specific condition when the speculator induces wages to be higher. To reiterate, we keep things transparent by introducing a simple one-period representative agent model. We discuss relaxing these assumptions in Section 3.

In the representative agent model, assume the worker maximizes utility $u(c, l)$, which is a function of his choice of consumption and leisure, or $c$ and $l$, respectively. The worker is subject to a budget constraint $c \leq w(T-l)+\pi$ where $T$ is the worker's endowment of time, $w$ is the wage paid per unit of time worked and $\pi$ are the profits the firm distributes to the worker. The monopoly's (or firm's) production function has constant returns to labor, or $F(n)=z n$, where $z$ is output per unit of labor and $n$ is the quantity of labor hired. Constant returns to scale simplifies the analysis as firm entry can be ignored in the sense of minimizing average cost. ${ }^{1}$ Capital can be add too without any loss of generality. If the the worker is offered a wage $w$ per unit of labor, then firm profits are $\pi=z n-w n$. It is assumed the firm maximizes profits and distributes the profits to the share holders. To close the economy, we assume the worker is the shareholder but take the profits as fixed. The firm does not maximize worker utility even though the firm's profits are distributed to the worker. The assumption is effectively the same as an overlapping generations model where the old generation sells ownership of the firm to the young generation every period and solves for the optimal level of labor to maximize consumption while old. We exclude an overlapping generation model because it unnecessarily complicates the analysis. Furthermore, our focus is not on corporate governance.

In the spirit of such a model, we assume the profits of the firm are sold in a competitive market or exchange and a speculator can "short" the firm's stock on the exchange. We are referring to shorting as a situation where the seller of the short makes money when the value of the firm's stock, or profit in our case, falls. It will turn out the firm will not want to sell its stock on the exchange. However, it can be explicitly assumed within the representative agent model that the worker represents a continuum of workers. If such an assumption were made, then the firm (or old generation) would have to sell the firm's profits on the exchange if it hopes to acquire a non-zero sales price. Alternative assumptions could be made for why the firm sells shares on the exchange

\footnotetext{
${ }^{1}$ Adding a concave production function adds additional layers of complexity. The interesting thing in an environment with a concave production function is the speculator will be "pushing" the profits of the monopolist to zero as its ability to short sell increases. The issue is this might not be the efficient outcome if the monopolist is government sanctioned and entry cannot occur. That being said, one can consider the efficient amount of short selling to induce the monopolist to move towards the most efficient outcome.
} 
including the spreading of risk given multiple monopolies within a market exists, but we simply assume away the longer discussion to achieve the goal of transparency. In a similar way, we are assuming the exchange allows speculators and short selling in order to guarantee an accurate price for the firm's profits.

The timing of the model or game is (i) the firm offers a wage $w$ to maximize profits, then (ii) a large number of investors purchase the firm's profits, i.e., stock, at price $p$ while the speculator can sell the profits short at the same price, then (iii) the worker produces or the speculator reduces the firm's production by entering and price the good competitively, and finally (iv) the firm pays its profit to the investors, the speculator settles its short position, and the worker gets paid by the firm if he worked.

If the firm is maximizing its stock price in period (ii), then the introduction of the speculator could affect its actions. This is the result we are deriving. The actions the speculator can take are determined by the type of monopoly it is facing. We will first consider the simple case of a fixed cost of entry. The second case is where the the monopoly is government sanctioned.

In the first scenario, the market allows a new entrant if a fixed cost $F$ is paid. If a second firm enters, then we assume Bertrand competition between the two firms (this can be relaxed to a Cournot equilibrium and the general results hold). As a result, the fixed cost of entry deters an entrant. The primary determinant of whether the speculator can affect the decision of the firm depends upon the proportion of the firm's profits the speculator is capable of shorting. In reality, many exchanges have position limits and the speculator orchestrating the short and entry could be limited in their ability to enter a sufficiently large position. Furthermore, the actual market has (arguably) a price revealing feature and a larger than normal volume could drive down the price as it signals the entrance of the speculator. It is key that the speculator's action be anonymous. Thus, the speculator faces several factors that limit the size of the short. Taking these factors and our goal of transparency, we assume the speculator can short a proportion or multiple $\phi$ of the firm's profits at price $p$. If the speculator shorts more than $\phi$, then the price of the stock is zero. The price is zero because the investors will not pay $0<p$ as they know the speculator will be driving profits to zero. Due to competition on the exchange and the firm must sell ownership, we take the price of the firm's stock to be $p=z n-w n$ if $\phi p \leq F$ and zero otherwise. In words, investors on the exchange bid what the firm is worth, or $z n-w n$, unless a speculator has the incentive to short the firms stock and enter. If a speculator can profit from shorting the firm, or $\phi p>F$, then investors 
do not pay anything for the firm, or $p=0$, because they know its profits will be zero when the speculator enters. To reiterate, if the firm uses capital, then the price of the firm would equal the price of the capital rather than zero. However, this has been excluded for simplicity.

As a result of the set-up, the firm offers a wage $w^{*}$ to maximize profit taking the worker's and speculator's problem as given. Analytically, the firm

$$
\begin{gathered}
\max _{w} z n-w n, \\
\text { s.t. } \phi[z n-w n] \leq F \\
w=S(n) .
\end{gathered}
$$

where $S(n)=\frac{u_{2}(w n+\pi, T-n)}{u_{1}(w n+\pi, T-n)}$ represents the worker's supply of labor and the subscripts depict the partial derivative of each argument in the utility function. As the problem is relatively simple, we have taken the liberty to skip two steps and have immediately incorporated the final two stages of the game into the objective function of the firm, i.e., we are assuming a subgame perfect equilibrium and solving for it using backward induction. The firm moves first and its problem, given how the subsequent stages are played out, is represented in equation 1. The first constraint incorporates the threat of the speculator entering. The speculator's problem is simple. He enters if the profits from the short position outweigh the cost of entry. Also, he takes the maximum short position because Bertrand competition will drive profits to zero. The second constraint represents the fact that the worker maximizes his utility by choosing the optimal level of leisure given the offered wage $w$. The final step in solving for the equilibrium is to solve for $w^{*}$ using the firm's problem. If the worker's supply of labor contains the "standard" conditions, then the problem has a unique solution.

Proposition 1 If $S(0)=0, d S(n) / d n>0$ and $d^{2} S(n) / d n^{2}>0$, then the equilibrium $\left(w^{*}, n^{*}\right)$ exists and is unique.

Convexity and the initial condition are standard assumptions to insure a unique equilibrium exists in the problem without the short selling constraint. If the speculator constraint binds, then the linear constraint can easily be verified to have a unique solution. We assume from here on that the assumptions required for a unique equilibrium hold. We label the equilibrium with the binding "speculator constraint" as the short selling equilibrium. The speculator affects the monopolist's behavior, or the short selling equilibrium exists, under a certain condition. 
Proposition 2 If $z-\frac{d S\left(n^{0}\right)}{d} n^{0}<\frac{\phi z-F / n^{0}}{\phi}$ where $n^{0}$ satisfies $z-\frac{d S\left(n^{0}\right)}{d} n^{0}=S\left(n^{0}\right)$, then the short selling equilibrium results and the monopolist's behavior and rents are constrained.

The result is easily derived by evaluating whether the unconstrained solution violates the constraint. If the constraint is binding given the interior solution, then the monopolist's behavior and rents are constrained. The monopoly equilibrium, i.e., equilibrium without a binding speculator constraint, the short selling equilibrium and the competitive equilibrium ${ }^{2}$ can be described as

A. Competitive Equilibrium

- $w^{*}=z$ and

- $w^{*}=S\left(n^{*}\right)$

B. Short-Selling Equilibrium

- $w^{*}=\phi z-F / n^{*}$ and

- $w^{*}=S\left(n^{*}\right)$

C. Monopoly Equilibrium

- $w^{*}=z-n^{*} \frac{d S\left(n^{*}\right)}{d n^{*}}$ and

- $w^{*}=S\left(n^{*}\right)$

The purpose of this section is to provide a transparent theoretical argument. The transparency comes through in Figure 1 where we plot the different types of equilibria. Taking from classical economics, the competitive equilibrium is where marginal productivity equals the supply of labor. On the other extreme, the monopoly firm sets marginal revenue equal to marginal cost or $z=$ $S(n)+n * d S(n) / d n$. However, if the speculator's constraint is binding as we have drawn it, then the short selling equilibrium results and the firm raises its wage and hires more labor. Proposition 2 can easily be seen in the figure.

\section{Insert Table 1 Here}

\footnotetext{
${ }^{2}$ The competitive equilibrium is defined as the firm and worker taking the wage as given and the equilibrium $n^{*}$ and $w^{*}$ is determined where the amount of labor demanded by the firm equals the amount supplied by the worker.
} 
Two important results are left to highlight. First, as the ability of the speculator to short the firm increases, or $\phi$ approaches infinity, then the short selling equilibrium approaches the competitive equilibrium. It can be seen in Figure 1 or noting that the $\lim _{\phi \rightarrow \infty} \frac{\phi z n-F}{\phi z n}=z$. Second, market efficiency is achieved when $S\left(n^{*}\right)=z$. Therefore, an increase in the ability of the speculator to take a large anonymous short position increases welfare and in the limit insures efficiency in the canonical sense. As you can see, $\phi$ is a critical parameter of the model and it could be endogenized in multiple ways including how the exchange maximizes $\phi$ to attract traders and the firm. Alternatively, it could be chosen by a regulator to limit variation in the price of the firm's profits assuming the reduction of $\phi$ would limit variation. The discussion regarding $\phi$ is complicated and not well understood. As limits to short selling appear to exist, we take them as a parameter of the model.

Rather than focusing on the constraints of short selling, we consider an alternative situation where the firm is a government sanctioned monopolist. In other words, the speculator cannot enter and drive the wage to $z$. In such a case, the speculator can still reduce the firm's profits by coordinating the firm's workers (or buyers if we were to consider the alternative set-up). Specifically, we assume the speculator can offer workers $w+\varepsilon$, and if it does, then the workers will not produce and instead take the speculator's payment. The payment $\varepsilon$ represents the premium the speculator must pay to ensure the worker does not produce, i.e., boycott working via shirking, striking or quitting. The primary determinant of whether the speculator can affect the decision of the firm depends upon the proportion of the firm's profits the speculator is capable of shorting. Again, we assume the speculator can short a proportion or multiple $\phi$ of the firm's profits at price $p$. Similar to before, the speculator enters the market if it is profitable for him to do so, or if $\phi p \leq(w+\varepsilon) n$.

Following the previous discussion with a fixed cost of entry, the firm's problem in the government sanctioned case with a coordinating speculator is

$$
\begin{gathered}
\max _{w} z n-w n, \\
\text { s.t. } \phi[z n-w n] \leq(w+\varepsilon) n \\
w=S(n) .
\end{gathered}
$$

where again $S(n)=\frac{u_{2}(w n+\pi, T-n)}{u_{1}(w n+\pi, T-n)}$ represents the worker's supply of labor. The key difference between this case and the fixed cost of entry case is the short selling constraint. ${ }^{3}$ However, the

\footnotetext{
${ }^{3}$ Note the speculator's problem is simplified. If the speculator enters, then it shorts the maximum amount and
} 
sufficient conditions for existence and uniqueness of the equilibrium are the same. The condition under which a speculator enters changes to

Proposition 3 If $z-\frac{d S\left(n^{*}\right)}{d} n^{*}<\frac{\phi z-\varepsilon}{1+\phi}$, then the short selling equilibrium results and the monopolist's behavior and rents are constrained.

The short selling equilibrium becomes

$$
\begin{aligned}
& \text { - } w^{*}=\frac{\phi z-\varepsilon}{1+\phi} \text { and } \\
& \text { - } w^{*}=S\left(n^{*}\right)
\end{aligned}
$$

and the equilibrium figure is in some sense simplified as seen in Figure 2. As before, if the coordinating speculator constraint binds, then the firm offers a higher wage and hires more workers. Also, if the speculator's ability to short-sell grows, then the market becomes more efficient and in the limit the market approaches the competitive and efficient equilibrium.

\section{Insert Table 2 Here}

To review, we covered two different situations where a monopoly arises and how a speculator can short-sell the firm's profits and use the funds to move the monopolist's behavior toward the competitive and efficient outcome. Note the two cases can easily be tied together. For instance, the speculator might prefer to coordinate the worker rather than pay the fixed cost to enter. Therefore, the firm could face two constraints and the minimum of the two constraints applies. However, the fixed cost to entry problem might not apply if the monopoly is government sanctioned.

\section{Discussion}

One can consider a multitude of extensions to the basic model. The extensions we have discussed are overlapping generations and why the firm is publicly traded, a concave production function, the inclusion of capital in the production function, the type of competition that occurs if a firm enters, and endogenizing or smoothing $\phi$. However, these assumptions do not make a meaningful

enters. It shorts the maximum amount because inducing a worker to strike will result in profits for every fixed amount the speculator shorts. Furthermore, the speculator induces the worker to completely shirk because if it induces the worker to shirk in the first unit of time, then it is equally profitable to induce the worker to shirk as the benefits and costs, or $z$ and $w+\varepsilon$, are constant. 
impact on the result although they can limit it as in the case of a concave production function with a government sanctioned monopoly. The result being if workers are paid below their productivity (or consumers pay more than the cost of production), then the publicly traded profits from the firm can be leveraged to either enter and drive the price to the efficient level or coordinate the firm's counter-party to boycott. A wide variety of other extensions can be included. For instance, the speculator may be risk averse. Thus, the short position acquired by the speculator could include a premium if one of the parameters, such as the firm's profit, contains a stochastic component. However, this could be mitigated in several ways. First, the speculator could hedge the share price against macroeconomic or sector specific shocks. Furthermore, the speculator could enter into the position with many investors. Likely the most fundamental issue of engaging the strategy, and not economic related, is the interpretation of the speculator's actions. Specifically, they could be deemed as extortion and incur government penalties. From an economist's perspective, it is a shift toward a competitive market. From a legal perspective, we note it does not appear to violate any Security and Exchange Commission regulations. As the approach has never been tried or even discussed to our knowledge, then we cannot clearly predict how the courts would judge the matter. However, the argument above suggests the court should rule in favor of its practice rather than against it as it reduces monopoly power.

In terms of testing the model, the model will never result in a speculator shorting a firm as the firm pays a sufficiently high wage in advance of such an action. Therefore, the simple model we describe is not directly testable. The model does suggest labor, at publicly traded firms, is paid a higher wage. However, such a result could be due to a variety of reasons. Therefore, the hypothesis cannot be unequivocally supported empirically. With this in mind, the primary purpose of our writing down a model is to describe a new argument for short selling and provide the condition where it will encourage the market to approach an efficient outcome. In the spirit of testing the model, one can ask whether it is reasonable to think the restriction might be binding? The fixed cost and short selling constraint may hold in many situations. If $\phi$ ranges between 3 and $10 \%$, then depending upon the industry it can easily be argued the fixed cost of entry is above or below that range. An online firm such as Netflix is a potential target for a speculator assuming they extract monopoly rents. Specifically, in July of 2011, the firm's short interest was roughly $20 \%$ with a market capitalization of $\$ 15$ billion. It appears feasible that a speculator could have entered and driven down the price as its book value during that time was around \$0.4 
billion. The coordinating assumption and condition is harder to verify. However, workers are routinely coordinated in the form of unions and such actions offer opportunities for unions to profit. In Baumann and Engelhardt [2012], the argument is made that the short selling constraint could bind in the case of several large publicly traded firms. In the end, the constraint might not bind in many current situations. However, if $\phi$ is sufficiently large, then the constraint will bind. Thus, the argument suggests antitrust actions should encourage short selling and other profitable opportunities for firms to enter and drive prices down. In the case of scale economies were one firm is optimal, the short selling constraint will still drive the price down without entrants as shown in the case with insurmountable barriers to entry. In other words, antitrust action can look to the market to solve economic inefficiencies rather than imposing limitations on firm size.

To conclude, we have shown in a simple model that the ability to short a firm's profitability results in constraining a monopoly's behavior and drives its pricing to the competitive and efficient equilibrium. Our findings posit a completely new approach to antitrust. The approach is to eliminate monopoly power by requiring monopoly firms to be sold publicly and allow speculators to take sufficiently large short selling positions and profit by driving the monopoly's good to the competitive price.

\section{References}

Robert Baumann and Bryan Engelhardt. Unionization via the Stock Market. Working Paper, 2012.

Ronald L. Coase. The Problem of Social Cost. Journal of Law and Economics, 3:1-44, 1960.

Thomas I Renstrom and Erkan Yalcin. Endogenous Firm Objectives. Journal of Public Economic Theory, 5:67-94, 2003. 
Figure 1: Equilibrium

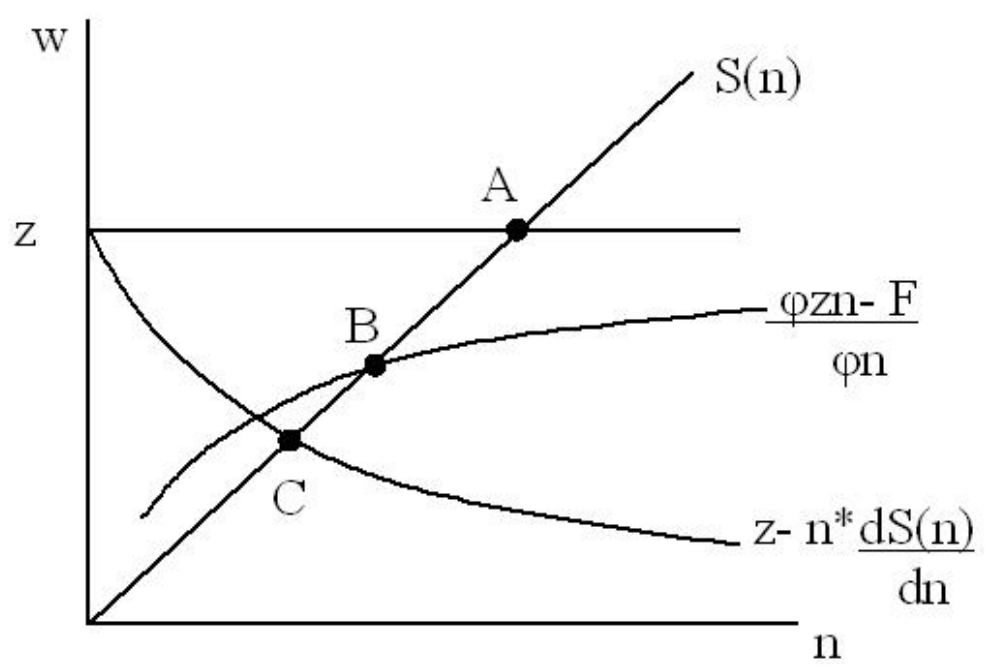

$\mathrm{A}=$ Competitive Equilibrium

$\mathrm{B}=$ Short-Selling Equilibrium

$\mathrm{C}=$ Monopoly Equilibrium

Figure 2: Equilibrium

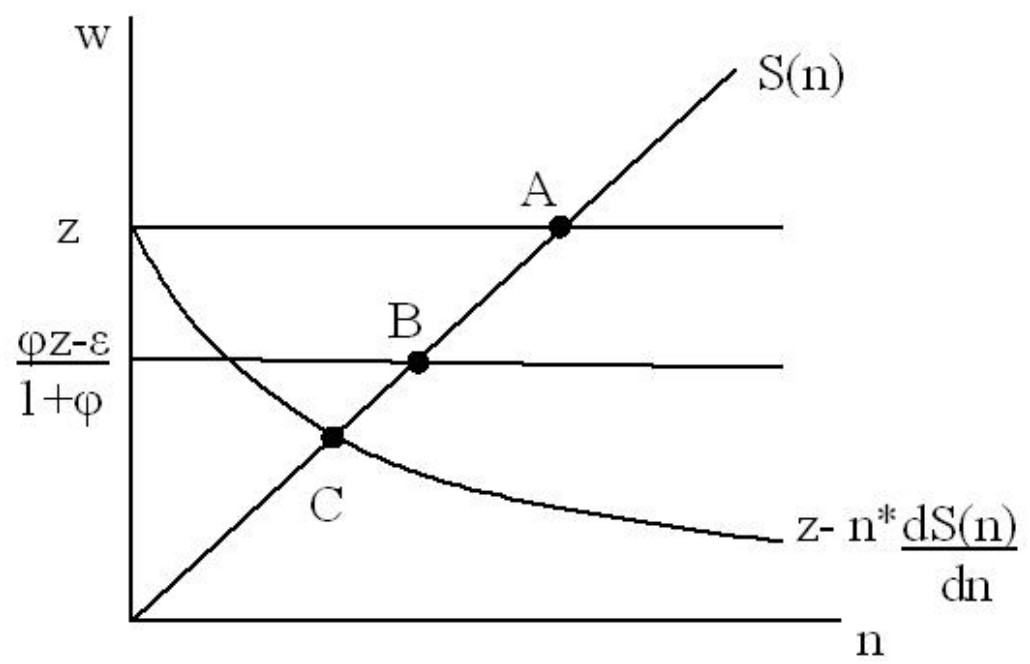

$\mathrm{A}=$ Competitive Equilibrium

$\mathrm{B}=$ Short-Selling Equilibrium

$\mathrm{C}=$ Monopoly Equilibrium 